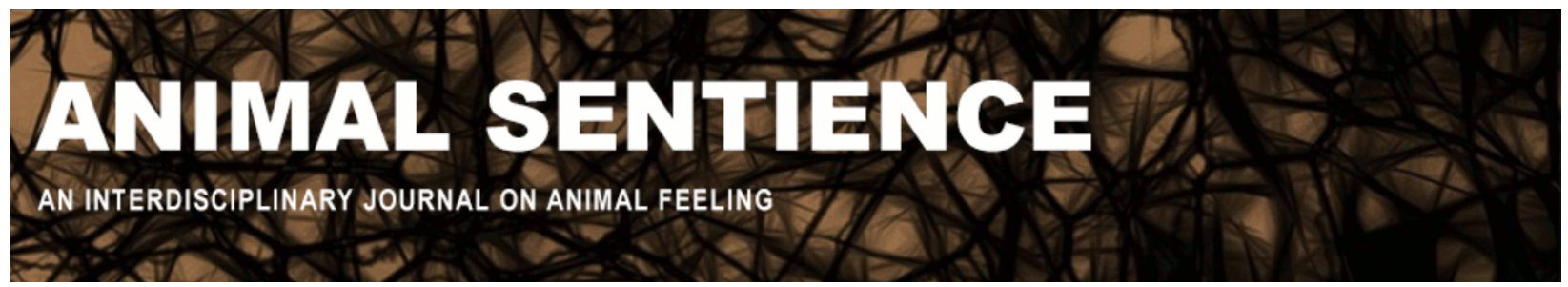

Gradidge, Sarah and Zawisza, Magdalena (2020) Toward a non-anthropocentric view on the environment and animal welfare: Possible psychological interventions. Animal Sentience 27(23)

DOI: $10.51291 / 2377-7478.1558$

Date of submission: 2020-02-21

Date of acceptance: 2020-02-26

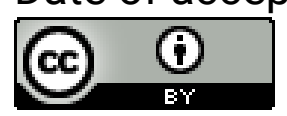




\title{
Toward a non-anthropocentric view on the environment and animal welfare: Possible psychological interventions
}

Commentary on Treves et al. on Just Preservation

\author{
Sarah Gradidge \& Magdalena Zawisza \\ Department of Psychology \\ Anglia Ruskin University, UK
}

\begin{abstract}
Treves, Santiago-Avila, and Lynn (2019) argue for adopting a non-anthropocentric worldview to prevent further environmental damage and lack of consideration for animals. We discuss psychological interventions that might help achieve this.
\end{abstract}

Sarah Gradidge, doctoral candidate in Psychology at ARU, Cambridge, does research on speciesism, its causes and interventions. Former editor of Psychobabble, she is also a member of The Vegan Society's Researcher Network. Website

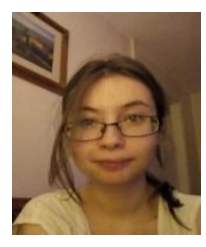

Magdalena Zawisza, Associate Professor/Reader at ARU, Cambridge has authored books on social, gender and consumer psychology. Website

Like previous commenters (e.g., Gray, 2019; Gupta, 2019; Tiffin, 2020), we welcome Treves et al.'s (2019) target article. All too often an emphasis on the importance of nature's preservation has been justified for anthropocentric interests only (see Washington, Taylor, Kopnina, Cryer, \& Piccolo, 2017). Treves et al. instead suggest that we must adopt a non-anthropocentric worldview to ensure the preservation of all species, both human and non-human. That is, we must apply "equal consideration of interests" (Singer, 1995, p. xxii) for all beings. Our treatment of the world, however, indicates that we view it anthropocentrically. One can think of numerous cases of human-caused extinctions of other species (non-human animals and plants; Braje \& Erlandson, 2013) and species' habitat destruction due to, for example, palm oil production (Strona, Stringer, Vieilledent, Szantoi, Garcia-Ulloa, \& Wich, 2018). Habitat loss and species extinction are examples of anthropocentric speciesism (Caviola \& Capraro, forthcoming): prejudice in favour of humans and against animals. Given its negative effects, the question of how a non-anthropocentric worldview can be cultivated and how anthropocentric speciesism can be overcome becomes important. Yet this important issue is left unanswered by Treves et al. Here we propose two practical psychological approaches which could help overcome anthropocentric speciesism: superordinate identity and superordinate generalization. We reported on a commonly used alternative intervention (factual appeals) in an earlier commentary (Gradidge \& Zawisza, 2019). 
Superordinate identity. Superordinate identity refers to incorporating outgroups (e.g., nonhumans such as animals) into an overarching inclusive ingroup (Gaertner, Dovidio, Anastasio, Bachman, \& Rust, 1993; Gaertner, Mann, Dovidio, Murrell, \& Pomare, 1990; Greenaway, Wright, Willingham, Reynolds, \& Haslam, 2015). For example, a superordinate identity of "humanity" unites humans of all ethnicities, genders, abilities, social classes, ages, social statuses and so forth into one group. Superordinate identities are usually fostered by meeting conditions of the Contact Hypothesis (Allport, 1954). These indicate that groups should be "cooperatively interdependent" and of equal status, among other features (Gaertner et al., 1993; Paluck, Green, \& Green, 2019), although these conditions may not be essential (Pettigrew \& Tropp, 2006). Encouraging superordinate identities encompassing humanity improves perceptions of human groups that are highly discriminated-against (e.g., decreases racism; Gaertner \& Dovidio, 2005).

An inclusive superordinate identity for all species (e.g., as joint inhabitants of the Earth) may encourage positive perceptions of all species, human and non-human. Preliminary research (Auger \& Amiot, 2016) suggests that the more contact we have with animals, the more we identify with them. Greater identification with animals is in turn associated with more positive perceptions of animals (Amiot \& Bastian, 2017; Bastian \& Amiot, 2019). Research is needed, however, to explicitly test interventions involving superordinate identities including humans and other animals. Such interventions may encourage positive contact (real or imagined) with animals as a whole group. Auger \& Amiot (2019b), for example, used an imagined intergroup contact intervention for dogs and cows for this purpose. A similar imagined intergroup contact intervention could be used for all animals as a group. Alternatively, interventions may emphasise traits, interests and goals that are shared by humans and animals. Whereas these kinds of intervention have shown promise in reducing human-to-human prejudice (e.g., Sherif, 1967; Adachi, Hodson, \& Hoffarth, 2015; Adachi, Hodson, Willoughby, Blank, \& Ha, 2016), they have not yet been tested in the context of speciesism. One could attempt to reduce speciesism by highlighting our shared interest in protecting and inhabiting Earth, as opposed to emphasizing dissimilar traits and conflicts of interest between humans and animals (see Gupta, 2019). It may be beneficial to emphasize the Earth we share (shared trait) and what we all will lose if it becomes uninhabitable (shared interest).

Superordinate generalization. An alternative to superordinate identity interventions is superordinate generalization: People may generalize their positive perceptions of "pet" animals to other animals. This is known as the pets as ambassadors hypothesis (Auger \& Amiot, 2015; Auger, Amiot, \& Bastian, 2015; Serpell \& Paul, 1994). Some of our own preliminary work (Gradidge, Zawisza, Harvey, \& McDermott, in preparation) suggests that the greater perceived pet status of dogs predicts more positive perceptions of both dogs and pigs, supporting this generalization effect. Further support comes from Auger and Amiot (2015, 2016, 2019a), who found that pet ownership and greater contact with pets predicted greater identification with animals. They also found that imagined intergroup contact interventions for dogs or cows increased identification with the animal's subgroup ("pets" or "farm" animals) and led to more prosocial behavioural intentions towards animals as a whole (Auger \& Amiot, 2019b). Thus, animal ambassadors do not need to be "pet" animals, although further research is needed to compare "pet" versus "non-pet" ambassadors. We also need to investigate when, how and why superordinate generalization occurs. Our studies (Gradidge et al., in preparation) showed that 
greater familiarity with dogs predicted greater perceived warmth of dogs, but not pigs, indicating that there may be limitations to the generalization effect. If that is so, further research on how to overcome these boundary conditions would be useful.

Conclusion. In this commentary, we have outlined two promising ways in which Treves et al.'s goal to reduce anthropocentric speciesism could be realised. It is not yet clear (a) whether superordinate identity interventions improve perceptions of and behaviors towards animals (as opposed to people) and (b) in what situations and why are superordinate identity or superordinate generalization interventions effective? We hope this commentary inspires more researchers to investigate the most effective interventions to reduce anthropocentric speciesism.

\section{References}

Adachi, P. J., Hodson, G., \& Hoffarth, M. R. (2015). Video game play and intergroup relations: Real world implications for prejudice and discrimination. Aggression and Violent Behavior, 25, 227-236.

Adachi, P. J., Hodson, G., Willoughby, T., Blank, C., \& Ha, A. (2016). From outgroups to allied forces: Effect of intergroup cooperation in violent and nonviolent video games on boosting favorable outgroup attitudes. Journal of Experimental Psychology, 145(3), 259.

Allport, G. W. (1954). The Nature of Prejudice. Reading, MA: Addison-Wesley.

Amiot, C. E., \& Bastian, B. (2017). Solidarity with animals: Assessing a relevant dimension of social identification with animals. PLoS One, 12(1), e0168184.

Auger, B., \& Amiot, C. E. (2015). Can pets facilitate identification with other animals? Testing the pets as ambassador hypothesis. Poster presented at the 75th Annual Convention of the Canadian Psychological Association, Ottawa, ON.

Auger, B., \& Amiot, C. E. (2016). Are all animals equal? Testing how contact with different animal types is associated with identification with animals. Poster presented at the 17th Annual Convention of the Society for Personality and Social Psychology, San Diego, CA.

Auger, B., \& Amiot, C. E. (2019a). Testing the roles of intergroup anxiety and inclusion of animals in the self as mechanisms that underpin the "pets as ambassadors" effect. Anthrozoös, 32(1), 5-21.

Auger, B., \& Amiot, C. E. (2019b). The impact of imagined contact in the realm of human-animal relations: Investigating a superordinate generalization effect involving both valued and devalued animals. Journal of Experimental Social Psychology, 85, 103872.

Auger, B., Amiot, C. E., \& Bastian, B. (2015). Extending the pets as ambassadors hypothesis. Poster presented at the International Society of Anthrozoology (ISAZ) Annual Conference, New York, NY.

Bastian B., \& Amiot, C. E. (2019). The animal in me. In Dhont, K., \& Hodson, G. (Eds.), Why We Love and Exploit Animals (pp. 9-28). London: Routledge.

Braje, T. J., \& Erlandson, J. M. (2013). Human acceleration of animal and plant extinctions: A Late Pleistocene, Holocene, and Anthropocene continuum. Anthropocene, 4, 14-23.

Caviola, L., \& Capraro, V. (forthcoming). Liking but devaluing animals: Emotional and deliberative paths to speciesism. Social Psychological and Personality Science. 
Gaertner, S. L., \& Dovidio, J. F. (2005). Understanding and addressing contemporary racism: From aversive racism to the common ingroup identity model. Journal of Social Issues, 61(3), 615-639.

Gaertner, S. L., Dovidio, J. F., Anastasio, P. A., Bachman, B. A., \& Rust, M. C. (1993). The common ingroup identity model: Recategorization and the reduction of intergroup bias. European Review of Social Psychology, 4(1), 1-26.

Gaertner, S. L., Mann, J. A., Dovidio, J. F., Murrell, A. J., \& Pomare, M. (1990). How does cooperation reduce intergroup bias? Journal of Personality and Social Psychology, 59(4), 692704.

Gradidge, S., \& Zawisza, M. (2019). Why factual appeals may fail. Animal Sentience 25(42).

Gradidge, S., Zawisza, M., Harvey, A. H., \& McDermott, D. (in preparation). Investigating causes of speciesism.

Gray, J. (2019). Granting political representation to non-humans. Animal Sentience 27(5).

Greenaway, K. H., Wright, R. G., Willingham, J., Reynolds, K. J., \& Haslam, S. A. (2015). Shared identity is key to effective communication. Personality and Social Psychology Bulletin, 41(2), 171-182.

Gupta, R. (2019). Just preservation: From vision to reality. Animal Sentience 27(9).

Paluck, E. L., Green, S. A., \& Green, D. P. (2019). The contact hypothesis re-evaluated. Behavioural Public Policy, 3(2), 129-158.

Pettigrew, T. F., \& Tropp, L. R. (2006). A meta-analytic test of intergroup contact theory. Journal of Personality and Social Psychology, 90(5), 751.

Serpell, J. A., \& Paul, E. (1994). Pets and the development of positive attitudes to animals. In Manning, A., \& Serpell, J. (Eds.), Animals and Human Society: Changing Perspectives (pp. 127-144). London: Routledge.

Sherif, M. (1967). Group Conflict and Competition. London: Routledge \& Kegan Paul.

Singer, P. (1995). Animal Liberation. London, UK: Random House.

Strona, G., Stringer, S. D., Vieilledent, G., Szantoi, Z., Garcia-Ulloa, J., \& Wich, S. A. (2018). Small room for compromise between oil palm cultivation and primate conservation in Africa.

Proceedings of the National Academy of Sciences, 115(35), 8811-8816.

Tiffin, H. (2020). Human interests. Animal Sentience 27(12).

Treves, A., Santiago-Ávila, F. J., \& Lynn, W. S. (2019). Just preservation. Animal Sentience 27(1).

Washington, W., Taylor, B., Kopnina, H. N., Cryer, P., \& Piccolo, J. J. (2017). Why ecocentrism is the key pathway to sustainability. Ecological Citizen, 1, 7. 


\section{Call for Papers}

Special Issue of the Journal of Consciousness Studies

Plant Sentience: Theoretical and Empirical Issues

Guest Editors: Vicente Raja (Rotman Institute of Philosophy, Western University) Miguel Segundo-Ortin (School of Liberal Arts, University of Wollongong)

In this special issue, we address the issue of plant sentience/consciousness from different disciplines that combine both theoretical and empirical perspectives. Some of the questions to be addressed in the special issue include the following:

- Plants exhibit interesting behaviors; does this entail that they are conscious to some extent?

- What are the requirements for a living organism to be conscious? Do plants meet these requirements?

- What does the possibility of plant sentience/consciousness entail for the study of the evolution of consciousness?

- Is it just a categorical mistake to attribute consciousness to plants?

- Can we talk about different levels or degrees of consciousness?

\section{How to submit?}

\section{Deadline: June 1st, 2020}

Please submit your papers (max. 9000 words including footnotes, references, abstract, etc.) to vgalian@uwo.ca with subject "Paper Special Issue JCS".

For more information, including bibliography and more detailed descriptions of the topics and questions to be addressed in the papers submitted to the special issue, please contact the guest editors atvgalian@uwo.ca (Vicente) or ms0693@uowmail.edu.au (Miguel). 